\title{
Analisis perbandingan komunikasi satelit Frekuensi C-Band Dan KA-Band Di Indonesia
}

\author{
Tanridio Silviati \\ Delfina Abdurrahman \\ Program Studi Teknik Elektro \\ Fakultas Teknik UMI \\ Makassar, Indonesia \\ tanridio@yahoo.com
}

\author{
Salmiah \\ Program Studi Teknik Elektro \\ Fakultas Teknik UMI \\ Makassar, Indonesia \\ mia_elektro@yahoo.co.id
}

\author{
Saidah Suyuti \\ Program Studi Teknik Elektro \\ Fakultas Teknik UMI \\ Makassar, Indonesia \\ saidah@ymail.com
}

\begin{abstract}
This paper analyzes the comparison of data communications using GEO satellites between $\mathrm{C}$-band and Ka-band frequencies in Indonesia which has a tropical rain climate. The data communication uses QPSK modulation on the path of four earth stations by paying attention to six variations of observation time. Parameters, C/ N, Eb/No and link margins, are applied to indicate the communication performance. This study shows that $\mathrm{C}$-band satellite communication can be implemented for all conditions, whereas in Ka-band the success of communication transfer cannot be accessed by all observation times.
\end{abstract}

Keywords: frequency, satellite, earth station, margin, availability, modulation.

\section{PENDAHULUAN}

Komunikasi di era milenial menuntut pertukaran informasi real time dengan kecepatan akses yang tinggi termasuk di Indonesia. Indonesia adalah negara tropis dengan tingkat curah hujan tinggi yang juga merupakan negara maritim membutuhkan satelit untuk pertukaran informasi secara cepat. Satelit komersil yang bekerja dipita frekuensi Cband sudah sejak awal melayani jalur komunikasi di Indonesia. Saat ini, banyak negara-negara asing berlomba-lomba meluncurkan satelit Ka-band. Sayangnya, curah hujan yang tinggi menjadi kendala penerapan satelit Ka-band tersebut sehingga diperlukan berbagai persyaratan dalam merancang komunikasi data menggunakan satelit Ka-band [1].

Pelayanan dan performansi komunikasi satelit sangat tergantung erat dengan faktor-faktor jumlah redaman-redaman yang muncul sepanjang jalur komunikasi (lintasan stasiun bumi-satelit-stasiun bumi), besar daya pancar dan penguatan antena, serta pemilihan teknik modulasi. Oleh karena itu paper ini bertujuan untuk menganalisis perbandingan komunikasi satelit berfrekuensi Cband dan Ka-band di empat wilayah Indonesia dengan mengetahui nilai-nilai $\mathrm{C} / \mathrm{N}, \mathrm{Eb} / \mathrm{No}$, margin dan availability jalur komunikasi menggunakan modulasi [2].

Penelitian ini menempatkan satelit GEO berfrekuensi C-band dan Ka-band dengan satu stasiun bumi Hub (Jakarta) dan tiga stasiun bumi lainnya (Medan, Surabaya dan Makassar) dengan menggunakan teknik modulasi digital QPSK.

Orbit satelit terletak di $108^{\circ} \mathrm{BT}$ dengan pita frekuensi C dan Ka. Satelit tersebut untuk frekuensi $\mathrm{C}$ mempunyai EIRP 55,6 dBW dan figure of merit 22,7 dBK, sedangkan frekuensi yang lainnya menggunakan EIRP 73,1 dBw dan G/T 19,7 dB/K. Sementara itu, stasiun-stasiun bumi yang ada masing-masing berspesifikasi sesuai tabel di bawah ini:

Tabel 1. EIRP dan G/T stasiun bumi

\begin{tabular}{|l|r|r|r|r|}
\hline \multirow{2}{*}{ Stasiun Bumi } & \multicolumn{2}{|c|}{ Frekuensi C-band } & \multicolumn{2}{|c|}{ Frekuensi Ka-band } \\
\cline { 2 - 5 } & EIRP(dBW) & G/T (dB/K) & EIRP(dBW) & G/T (dB/K) \\
\hline SB HUB & 87,7 & 31 & 79,3 & 32,7 \\
\hline SB lainnya & 82,4 & 27 & 59,8 & 16,4 \\
\hline
\end{tabular}

Spesifikasi teknis satelit dan stasiun bumi merujuk pada satelit INTELSAT dan proyek WINDS. Jalur komunikasi $\mathrm{C}$-band dan Ka-band secara berturutturut bekerja pada frekuensi uplink $6 \mathrm{GHz}$ dan 28 $\mathrm{GHz}$ serta frekuensi downlink $4 \mathrm{GHz}$ dan $18 \mathrm{GHz}$ [3].

\section{REDAMAN JALUR KOMUNIKASI}

Redaman-redaman yang muncul pada lintasan komunikasi satelit terdiri atas free space loss (FSL), redaman hujan, redaman awan, redaman gas-gas atmosfir dan scintillation dilapisan troposfer[3].

\section{a. Redaman Ruang Bebas (FSL)}

Redaman ruang bebas merupakan redaman yang dipengaruhi oleh frekuensi kerja dan jarak antara stasiun bumi - satelit. Besar redaman FSL dinyatakan dengan menggunakan persamaan [4]

$$
F S L=92,4+20 \log f+20 \log d
$$

Frekuensi menyumbang redaman terbesar pada FSL ini. Komunikasi satelit yang menggunakan pita frekuensi Ka mengalami redaman lebih besar $13 \mathrm{~dB}$ dibandingkan frekuensi C-band [2].

Redaman FSL komunikasi satelit C-band dan Kaband untuk komunikasi keempat stasiun bumi ke satelit terlihat seperti pada tabel 2. 
Tabel 2. Redaman ruang bebas

\begin{tabular}{|c|c|c|r|}
\hline \multirow{2}{*}{$\begin{array}{c}\text { Stasiun } \\
\text { Bumi }\end{array}$} & \multirow{2}{*}{ Jalur } & \multicolumn{2}{|c|}{ FSL (dB) } \\
\cline { 3 - 4 } Jakarta & C-Band & Ka-Band \\
\cline { 2 - 4 } & Downink & 199,0440 & 212,4241 \\
\hline \multirow{2}{*}{ Surabaya } & Uplink & 195,5222 & 208,5864 \\
\cline { 2 - 4 } & Downlink & 199,0533 & 212,4335 \\
\hline \multirow{2}{*}{ Medan } & Uplink & 195,5315 & 208,5958 \\
\cline { 2 - 4 } & Downlink & 195,5390 & 212,4409 \\
\hline \multirow{2}{*}{ Makassar } & Uplink & 199,0758 & 212,4559 \\
\cline { 2 - 4 } & Downlink & 195,5540 & 208,6182 \\
\hline
\end{tabular}

\section{b. Redaman Hujan}

Redaman hujan juga menjadi perhatian dalam komunikasi satelit ini karena terjadi pelemahan sinyal yang signifikan. Para peneliti terdahulu telah melakukan banyak kajian tentang redaman hujan yang memberikan beberapa metode untuk memprediksinya [5] [6]. Rekomendasi ITU-R P.618-12 dijadikan landasan perhitungan redaman hujan pada penelitian ini. Redaman-redaman hujan untuk kedua komunikasi satelit berbeda frekuensi dapat dilihat pada tabel 3 dan tabel 4 berikut ini.

Tabel 3. Redaman hujan komunikasi satelit C-band

\begin{tabular}{|c|c|c|c|c|c|c|c|}
\hline \multirow{2}{*}{$\begin{array}{c}\text { Stasiun } \\
\text { Bumi }\end{array}$} & \multirow{2}{*}{ Jalur } & \multicolumn{5}{|c|}{ Redaman Hujan Frekuensi C-Band (dB) } \\
\cline { 3 - 8 } & & $\mathbf{0 . 0 1 \%}$ & $\mathbf{0 . 5 \%}$ & $\mathbf{0 . 6 \%}$ & $\mathbf{0 . 7 \%}$ & $\mathbf{0 . 8 \%}$ & $\mathbf{0 . 9 \%}$ \\
\hline \multirow{2}{*}{ Jakarta } & Uplink & 0,8247 & 0,0898 & 0,0743 & 0,0624 & 0,0529 & 0,0452 \\
\cline { 2 - 8 } & Downlink & 0,1532 & 0,0124 & 0,0101 & 0,0084 & 0,0071 & 0,0060 \\
\hline \multirow{2}{*}{ Surabaya } & Uplink & 0,9156 & 0,1003 & 0,0833 & 0,0702 & 0,0597 & 0,0511 \\
\cline { 2 - 8 } & Downlink & 0,1556 & 0,0125 & 0,0102 & 0,0085 & 0,0072 & 0,0061 \\
\hline \multirow{2}{*}{ Medan } & Uplink & 1,0691 & 0,1242 & 0,1027 & 0,0861 & 0,0728 & 0,0620 \\
\cline { 2 - 8 } & Downlink & 0,1830 & 0,0156 & 0,0127 & 0,0105 & 0,0088 & 0,0074 \\
\hline \multirow{2}{*}{ Makassar } & Uplink & 0,9277 & 0,1034 & 0,0857 & 0,0720 & 0,0610 & 0,0521 \\
\cline { 2 - 7 } & Downlink & 0,1581 & 0,0129 & 0,0105 & 0,0088 & 0,0073 & 0,0062 \\
\hline
\end{tabular}

Tabel 4. Redaman hujan komunikasi satelit Ka-band

\begin{tabular}{|c|c|c|c|c|c|c|c|}
\hline \multirow{2}{*}{$\begin{array}{c}\text { Stasiun } \\
\text { Bumi }\end{array}$} & \multirow{2}{*}{ Jalur } & \multicolumn{5}{|c|}{ Redaman Hujan Frekuensi Ka-Band (dB) } \\
\cline { 3 - 8 } & & $\mathbf{0 . 0 1 \%}$ & $\mathbf{0 . 5} \%$ & $\mathbf{0 . 6 \%}$ & $\mathbf{0 . 7 \%}$ & $\mathbf{0 . 8 \%}$ & $\mathbf{0 . 9 \%}$ \\
\hline \multirow{2}{*}{ Jakarta } & Uplink & 23,0157 & 4,5013 & 3,8313 & 3,2914 & 2,8466 & 2,4744 \\
\cline { 2 - 8 } & Downlink & 11,7990 & 2,0515 & 1,7366 & 1,4850 & 1,2792 & 1,1080 \\
\hline \multirow{2}{*}{ Surabaya } & Uplink & 26,3392 & 5,2137 & 4,4510 & 3,8357 & 3,3280 & 2,9022 \\
\cline { 2 - 8 } & Downlink & 13,3387 & 2,3423 & 1,9885 & 1,7055 & 1,4737 & 1,2806 \\
\hline \multirow{2}{*}{ Medan } & Uplink & 30,0741 & 6,2852 & 5,3446 & 4,5836 & 3,9550 & 3,4283 \\
\cline { 2 - 8 } & Downlink & 15,2157 & 2,8205 & 2,3850 & 2,0358 & 1,7494 & 1,5110 \\
\hline \multirow{2}{*}{ Makassar } & Uplink & 26,7552 & 5,3913 & 4,5919 & 3,9465 & 3,4140 & 2,9677 \\
\cline { 2 - 8 } & Downlink & 13,4995 & 2,4116 & 2,0425 & 1,7471 & 1,5052 & 1,3037 \\
\hline
\end{tabular}

\section{c. Redaman Lainnya}

Redaman-redaman lainnya berupa redaman yang timbul karena faktor pekatnya awan, gas-gas yang ada dilapisan atmosfer dan scintillation yang terdapat di troposfer. Redaman awan diperoleh dengan mengikuti rekomendasi ITU-R P. 860-6. Sementara itu, besaran redaman atmosfer sebagian besar timbul karena redaman gas oksigen dan uap air yang diperoleh dengan mengikuti rekomendasirekomendasi ITU-R P. 835-5 dan ITU-R P. 676-7. Gabungan rekomendasi-rekomendasi ITU-R P. 835-
5, ITU-R 453 dan ITU R P. 618-12 menjadi rujukan untuk mengetahui redaman scintillation.

Redaman-redaman ini dapat dilihat pada kedua tabel berikut ini.

Tabel 5 Gabungan redaman awan, atmosfer dan scintillation untuk komunikasi satelit C-band

\begin{tabular}{|c|c|c|c|c|c|c|c|}
\hline \multirow{2}{*}{$\begin{array}{c}\text { Stasiun } \\
\text { Bumi }\end{array}$} & \multirow{2}{*}{ Jalur } & \multicolumn{5}{|c|}{ Redaman Lainnya Frekuensi C-Band (dB) } \\
\cline { 3 - 8 } & & $\mathbf{0 . 0 1 \%}$ & $\mathbf{0 . 5} \%$ & $\mathbf{0 . 6} \%$ & $\mathbf{0 . 7} \%$ & $\mathbf{0 . 8} \%$ & $\mathbf{0 . 9} \%$ \\
\hline \multirow{3}{*}{ Jakarta } & Uplink & 0,1228 & 0,0777 & 0,0760 & 0,0745 & 0,0733 & 0,0722 \\
\cline { 2 - 8 } & Downlink & 0,1037 & 0,0594 & 0,0577 & 0,0563 & 0,0551 & 0,0540 \\
\hline \multirow{2}{*}{ Surabaya } & Uplink & 0,3394 & 0,1838 & 0,1779 & 0,1730 & 0,1687 & 0,1650 \\
\cline { 2 - 8 } & Downlink & 0,2521 & 0,1321 & 0,1275 & 0,1237 & 0,1204 & 0,1175 \\
\hline \multirow{2}{*}{ Medan } & Uplink & 0,3413 & 0,1847 & 0,1787 & 0,1737 & 0,1695 & 0,1657 \\
\cline { 2 - 8 } & Downlink & 0,2536 & 0,1327 & 0,1281 & 0,1242 & 0,1209 & 0,1180 \\
\hline \multirow{2}{*}{ Makassar } & Uplink & 0,3464 & 0,1876 & 0,1815 & 0,1765 & 0,1722 & 0,1683 \\
\cline { 2 - 7 } & Downlink & 0,2574 & 0,1348 & 0,1301 & 0,1262 & 0,1229 & 0,1200 \\
\hline
\end{tabular}

Tabel 6 Gabungan redaman awan, atmosfer dan scintillation untuk komunikasi satelit Ka-band

\begin{tabular}{|c|c|c|c|c|c|c|c|}
\hline \multirow{2}{*}{$\begin{array}{c}\text { Stasiun } \\
\text { Bumi }\end{array}$} & \multirow{2}{*}{ Jalur } & \multicolumn{5}{|c|}{ Redaman Lainnya Frekuensi Ka-Band (dB) } \\
\cline { 3 - 8 } & & $\mathbf{0 . 0 1 \%}$ & $\mathbf{0 . 5} \%$ & $\mathbf{0 . 6 \%}$ & $\mathbf{0 . 7 \%}$ & $\mathbf{0 . 8} \%$ & $\mathbf{0 . 9} \%$ \\
\hline \multirow{3}{*}{ Jakarta } & Uplink & 0,2328 & 0,1315 & 0,1277 & 0,1244 & 0,1217 & 0,1193 \\
\cline { 2 - 8 } & Downlink & 0,2135 & 0,1131 & 0,1093 & 0,1061 & 0,1033 & 0,1009 \\
\hline \multirow{2}{*}{ Surabaya } & Uplink & 0,8013 & 0,4100 & 0,3951 & 0,3827 & 0,3720 & 0,3626 \\
\cline { 2 - 8 } & Downlink & 0,5909 & 0,2979 & 0,2868 & 0,2775 & 0,2695 & 0,2625 \\
\hline \multirow{2}{*}{ Medan } & Uplink & 0,8064 & 0,4123 & 0,3974 & 0,3849 & 0,3741 & 0,3646 \\
\cline { 2 - 8 } & Downlink & 0,5946 & 0,2996 & 0,2885 & 0,2791 & 0,2710 & 0,2639 \\
\hline \multirow{2}{*}{ Makassar } & Uplink & 0,8179 & 0,4184 & 0,4032 & 0,3906 & 0,3796 & 0,3701 \\
\cline { 2 - 8 } & Downlink & 0,6033 & 0,3041 & 0,2928 & 0,2833 & 0,2751 & 0,2680 \\
\hline
\end{tabular}

\section{LINK BUDGET}

Parameter-parameter EIRP, frekuensi kerja, redaman-redaman, figure of merit dan konstanta Boltzman dibutuhkan untuk menilai link budget (C/No) jalur komunikasi dari stasiun bumi ke satelit dan dari satelit ke stasiun bumi. Serangkaian publikasi unutk menganalisis performansi link budget pada komunikasi satelit telah dilakukan oleh beberapa peneliti terdahulu [7], [8] [9]. Persamaanpersamaan berikut ini digunakan untuk mengetahui besarnya link budget pada komunikasi satelit.

$$
\begin{aligned}
& \left(\frac{C}{N_{0}}\right)_{u}=E I R P_{S B}-F S L_{u}-(\text { redaman })+\left(\frac{G}{T}\right)_{S a t}-k \\
& \left(\frac{C}{N_{0}}\right)_{d}=E{ } P_{S a t}-F S L_{d}-(\text { redaman })+\left(\frac{G}{T}\right)_{S B}-k \\
& \frac{1}{\left(C / N_{o}\right)_{\text {tot }}}=\frac{1}{\left(C / N_{o}\right)_{u}}+\frac{1}{\left(C / N_{o}\right)_{d}} \\
& \operatorname{dan}\left(\frac{C}{N}\right)=\left(\frac{C}{N_{o}}\right)-10 \log B W
\end{aligned}
$$

Tabel-tabel 7, 8, 9 dan 10 menampilkan nilai link budget untuk arah uplink dan downlink dan total dari komunikasi satelit berpita frekuensi C dan Ka. 
Tabel 7. Link budget untuk uplink dan downlink komunikasi C-band

\begin{tabular}{|c|c|c|c|c|c|c|c|}
\hline \multirow{2}{*}{$\begin{array}{c}\text { Stasiun } \\
\text { Bumi }\end{array}$} & \multirow{2}{*}{ Jalur } & \multicolumn{6}{|c|}{ (C/N0) u\&d Frekuensi C-Band } \\
\cline { 3 - 8 } & & $99.99 \%$ & $99.5 \%$ & $99.4 \%$ & $99.3 \%$ & $99.2 \%$ & $99.1 \%$ \\
\hline \multirow{2}{*}{ Jakarta } & Uplink & 138,27 & 139,43 & 139,46 & 139,48 & 139,50 & 139,52 \\
\cline { 2 - 8 } & Downlink & 118,93 & 119,37 & 119,38 & 119,39 & 119,40 & 119,41 \\
\hline \multirow{2}{*}{ Surabaya } & Uplink & 133,39 & 134,36 & 134,39 & 134,40 & 134,42 & 134,43 \\
\cline { 2 - 8 } & Downlink & 115,26 & 115,52 & 115,53 & 115,54 & 115,54 & 115,54 \\
\hline \multirow{2}{*}{ Medan } & Uplink & 133,23 & 134,33 & 134,36 & 134,38 & 134,40 & 134,41 \\
\cline { 2 - 8 } & Downlink & 115,22 & 115,51 & 115,52 & 115,53 & 115,53 & 115,54 \\
\hline \multirow{2}{*}{ Makassar } & Uplink & 133,35 & 134,33 & 134,36 & 134,38 & 134,39 & 134,40 \\
\cline { 2 - 8 } & Downlink & 115,23 & 115,50 & 115,51 & 115,51 & 115,52 & 115,52 \\
\hline
\end{tabular}

Tabel 8. Link budget untuk uplink dan downlink komunikasi Ka-band

\begin{tabular}{|c|c|r|r|r|r|r|r|}
\hline \multirow{2}{*}{$\begin{array}{c}\text { Stasiun } \\
\text { Bumi }\end{array}$} & \multirow{2}{*}{ Jalur } & \multicolumn{6}{|c|}{ (C/N0) u\&d Frekuensi Ka-Band } \\
\cline { 3 - 8 } & & $\mathbf{9 9 . 9 9 \%}$ & $\mathbf{9 9 . 5 \%}$ & $\mathbf{9 9 . 4 \%}$ & $\mathbf{9 9 . 3 \%}$ & $\mathbf{9 9 . 2 \%}$ & $\mathbf{9 9 . 1 \%}$ \\
\hline \multirow{2}{*}{ Jakarta } & Uplink & 88,78 & 108,37 & 109,08 & 109,65 & 110,13 & 110,53 \\
\cline { 2 - 8 } & Downlink & 112,28 & 122,76 & 123,10 & 123,38 & 123,61 & 123,79 \\
\hline \multirow{2}{*}{ Surabaya } & Uplink & 67,28 & 88,80 & 89,58 & 90,21 & 90,72 & 91,16 \\
\cline { 2 - 8 } & Downlink & 95,30 & 106,59 & 106,95 & 107,24 & 107,48 & 107,68 \\
\hline \multirow{2}{*}{ Medan } & Uplink & 63,54 & 87,72 & 88,68 & 89,45 & 90,09 & 90,63 \\
\cline { 2 - 8 } & Downlink & 93,41 & 106,10 & 106,55 & 106,91 & 107,20 & 107,45 \\
\hline \multirow{2}{*}{ Makassar } & Uplink & 66,82 & 88,58 & 89,39 & 90,05 & 90,60 & 91,05 \\
\cline { 2 - 8 } & Downlink & 95,10 & 106,48 & 106,86 & 107,17 & 107,42 & 107,63 \\
\hline
\end{tabular}

Tabel 9. C/No total untuk komunikasi C-band

\begin{tabular}{|c|l|c|c|c|c|c|c|}
\hline \multicolumn{2}{|c|}{ Jalur Komunikasi } & \multicolumn{6}{|c|}{$(\mathbf{C} / \mathbf{N 0}$ )tot Frekuensi C-Band } \\
\hline Sumber & Tujuan & $\mathbf{9 9 . 9 9 \%}$ & $\mathbf{9 9 . 5 \%}$ & $\mathbf{9 9 . 4 \%}$ & $\mathbf{9 9 . 3 \%}$ & $\mathbf{9 9 . 2 \%}$ & $\mathbf{9 9 . 1 \%}$ \\
\hline \multirow{3}{*}{ Jakarta } & Surabaya & 115,24 & 115,51 & 115,51 & 115,52 & 115,52 & 115,53 \\
\cline { 2 - 8 } & Medan & 115,21 & 115,50 & 115,50 & 115,51 & 115,52 & 115,52 \\
\cline { 2 - 8 } & Makassar & 115,21 & 115,48 & 115,49 & 115,49 & 115,50 & 115,50 \\
\hline \multirow{4}{*}{ Surabaya } & Jakarta & 119,25 & 119,46 & 119,47 & 119,47 & 119,47 & 119,48 \\
\cline { 2 - 8 } & Medan & 115,16 & 115,46 & 115,46 & 115,47 & 115,48 & 115,48 \\
\cline { 2 - 8 } & Makassar & 115,16 & 115,44 & 115,45 & 115,46 & 115,46 & 115,46 \\
\hline \multirow{3}{*}{ Makassary } & Jakarta & 119,24 & 119,46 & 119,47 & 119,47 & 119,47 & 119,48 \\
\cline { 2 - 8 } & Surabaya & 115,19 & 115,47 & 115,47 & 115,48 & 115,48 & 115,49 \\
\cline { 2 - 8 } & Makassar & 115,16 & 115,44 & 115,45 & 115,46 & 115,46 & 115,46 \\
\cline { 2 - 8 } & Jakarta & 119,25 & 119,46 & 119,47 & 119,47 & 119,47 & 119,48 \\
\cline { 2 - 8 } & Medan & 115,19 & 115,47 & 115,47 & 115,48 & 115,48 & 115,49 \\
\cline { 2 - 8 } & 115,16 & 115,46 & 115,46 & 115,47 & 115,48 & 115,48 \\
\hline
\end{tabular}

Tabel 10. C/No total untuk komunikasi Ka-band

\begin{tabular}{|c|c|c|c|c|c|c|c|}
\hline \multicolumn{2}{|c|}{ Jalur Komunikasi } & \multicolumn{6}{|c|}{$(\mathrm{C} / \mathrm{N} 0)_{\text {tot }}$ Frekuensi Ka-Band (dB) } \\
\hline Sumber & Tujuan & $99.99 \%$ & $99.5 \%$ & $99.4 \%$ & $99.3 \%$ & $99.2 \%$ & $99.1 \%$ \\
\hline \multirow{3}{*}{ Jakarta } & Surabaya & 89,40 & 104,73 & 105,20 & 105,57 & 105,87 & 106,13 \\
\hline & Medan & 88,83 & 104,40 & 104,92 & 105,34 & 105,68 & 105,96 \\
\hline & Makassar & 89,35 & 104,66 & 105,14 & 105,52 & 105,83 & 106,09 \\
\hline \multirow{3}{*}{ Surabaya } & Jakarta & 67,28 & 88,80 & 89,58 & 90,20 & 90,72 & 91,16 \\
\hline & Medan & 67,27 & 88,72 & 89,49 & 90,11 & 90,63 & 91,06 \\
\hline & Makassar & 67,28 & 88,73 & 89,50 & 90,12 & 90,63 & 91,06 \\
\hline \multirow{3}{*}{ Medan } & Jakarta & 63,54 & 87,72 & 88,68 & 89,45 & 90,09 & 90,62 \\
\hline & Surabaya & 63,54 & 87,67 & 88,61 & 89,38 & 90,01 & 90,54 \\
\hline & Makassar & 63,54 & 87,66 & 88,61 & 89,38 & 90,01 & 90,54 \\
\hline \multirow{3}{*}{ Makassar } & Jakarta & 66,82 & 88,58 & 89,39 & 90,05 & 90,59 & 91,05 \\
\hline & Surabaya & 66,81 & 88,51 & 89,32 & 89,97 & 90,51 & 90,96 \\
\hline & Medan & 66,81 & 88,50 & 89,31 & 89,96 & 90,50 & 90,95 \\
\hline
\end{tabular}

\section{HASIL ANALISIS}

Analisis performansi lintasan komunikasi satelit bergantung pada beberapa parameter antara lain Eb/No dan margin rute komunikasi. Variabelvariabel tersebut sangat erat kaitannya dengan teknik modulasi yang dipergunakan.

Untuk mengetahui nilai Eb/No diperoleh dengan menggunakan persamaan-persamaan di bawah ini

$$
B W_{\text {occ }}=\frac{R_{s}}{F E C}(1+\alpha) \quad R_{s}=\frac{\left(R_{b}+\text { overhead }\right)}{n}
$$

dan $\frac{E_{b}}{N_{o}}=\frac{C}{N_{o}}-10 \log \left(R_{b}\right)$

Jumlah bit n untuk modulasi-modulasi QPSK adalah 2 .

Nilai Eb/No berdasarkan modulasi QPSK untuk kedua sistem komunikasi satelit berfrekuensi $\mathrm{C}$ dan Ka diperlihatkan oleh tabel-tabel berikut ini.

Tabel 11. Eb/No QPSK untuk C-band

\begin{tabular}{|c|l|c|c|c|c|c|c|}
\hline \multicolumn{2}{|c|}{ Jalur Komunikasi } & \multicolumn{5}{|c|}{$\begin{array}{c}\text { Eb/No modulasi QPSK } \\
\text { pada Frekuensi C-Band (dB) }\end{array}$} \\
\hline Asal & Tujuan & $\mathbf{9 9 . 9 9 \%}$ & $\mathbf{9 9 . 5 \%}$ & $\mathbf{9 9 . 4 \%}$ & $\mathbf{9 9 . 3 \%}$ & $\mathbf{9 9 . 2 \%}$ & $\mathbf{9 9 . 1 \%}$ \\
\hline \multirow{3}{*}{ Jakarta } & Surabaya & 38,933 & 39,198 & 39,205 & 39,211 & 39,215 & 39,219 \\
\cline { 2 - 9 } & Medan & 38,897 & 39,187 & 39,195 & 39,201 & 39,206 & 39,210 \\
\cline { 2 - 9 } & Makassar & 38,903 & 39,173 & 39,180 & 39,186 & 39,190 & 39,194 \\
\hline \multirow{3}{*}{ Surabaya } & Jakarta & 42,941 & 43,154 & 43,158 & 43,162 & 43,165 & 43,167 \\
\cline { 2 - 8 } & Medan & 38,849 & 39,147 & 39,155 & 39,161 & 39,166 & 39,171 \\
\cline { 2 - 8 } & Makassar & 38,855 & 39,133 & 39,140 & 39,146 & 39,151 & 39,155 \\
\hline \multirow{3}{*}{ Medan } & Jakarta & 42,935 & 43,153 & 43,158 & 43,161 & 43,164 & 43,167 \\
\cline { 2 - 8 } & Surabaya & 38,883 & 39,158 & 39,165 & 39,171 & 39,175 & 39,180 \\
\cline { 2 - 8 } & Makassar & 38,853 & 39,132 & 39,140 & 39,146 & 39,151 & 39,155 \\
\hline & Jakarta & 42,939 & 43,153 & 43,158 & 43,161 & 43,164 & 43,167 \\
\cline { 2 - 8 } & Surabaya & 38,884 & 39,158 & 39,165 & 39,171 & 39,175 & 39,179 \\
\cline { 2 - 8 } & Medan & 38,849 & 39,147 & 39,155 & 39,161 & 39,166 & 39,170 \\
\hline
\end{tabular}

Besaran nilai Eb/No bermodulasi QPSK pada komunikasi satelit berfrekuensi C-band memperlihatkan semua lintasan availability di atas Eb/No yang diinginkan yaitu $12 \mathrm{~dB}$. Sedangkan komunikasi bersatelit Ka-band tidak demikian.

Tabel 12. Eb/No QPSK untuk Ka-band

\begin{tabular}{|c|l|r|r|r|r|r|r|}
\hline \multirow{2}{*}{ Jalur Komunikasi } & \multicolumn{5}{|c|}{$\begin{array}{c}\text { Eb/No modulasi QPSK } \\
\text { pada Frekuensi Ka-Band (dB) }\end{array}$} \\
\hline Asal & Tujuan & $\mathbf{9 9 . 9 9 \%}$ & $\mathbf{9 9 . 5 \%}$ & $\mathbf{9 9 . 4 \%}$ & $\mathbf{9 9 . 3 \%}$ & $\mathbf{9 9 . 2} \%$ & $\mathbf{9 9 . 1 \%}$ \\
\hline \multirow{3}{*}{ Jakarta } & Surabaya & 13,089 & 28,416 & 28,886 & 29,260 & 29,565 & 29,819 \\
\cline { 2 - 9 } & Medan & 12,521 & 28,094 & 28,613 & 29,028 & 29,369 & 29,652 \\
\cline { 2 - 9 } & Makassar & 13,036 & 28,348 & 28,827 & 29,209 & 29,520 & 29,779 \\
\hline \multirow{3}{*}{ Surabaya } & Jakarta & $-9,026$ & 12,490 & 13,267 & 13,895 & 14,413 & 14,848 \\
\cline { 2 - 8 } & Medan & $-9,036$ & 12,411 & 13,183 & 13,805 & 14,318 & 14,749 \\
\cline { 2 - 8 } & Makassar & $-9,033$ & 12,418 & 13,189 & 13,810 & 14,323 & 14,753 \\
\hline \multirow{3}{*}{ Medan } & Jakarta & $-12,770$ & 11,411 & 12,367 & 13,140 & 13,779 & 14,315 \\
\cline { 2 - 8 } & Surabaya & $-12,773$ & 11,356 & 12,304 & 13,070 & 13,703 & 14,232 \\
\cline { 2 - 8 } & Makassar & $-12,773$ & 11,355 & 12,303 & 13,069 & 13,701 & 14,231 \\
\hline \multirow{3}{*}{ Makassar } & Jakarta & $-9,493$ & 12,269 & 13,084 & 13,742 & 14,285 & 14,741 \\
\cline { 2 - 8 } & Surabaya & $-9,499$ & 12,202 & 13,010 & 13,661 & 14,199 & 14,649 \\
\cline { 2 - 8 } & Medan & $-9,502$ & 12,194 & 13,002 & 13,655 & 14,193 & 14,644 \\
\hline
\end{tabular}

Selanjutnya, nilai margin pada jalur komunikasi dapat diketahui dengan menggunakan persamaanpersamaan berikut ini

$$
\begin{gathered}
\text { Margin }=\left(\frac{C}{N}\right)_{\text {total }}-\left(\frac{C}{N}\right)_{\text {required }} \\
\text { dengan }\left(\frac{C}{N}\right)_{\text {total }}=\left(\frac{C}{N_{0}}\right)_{\text {total }}-73,5835
\end{gathered}
$$

sedangkan $(\mathrm{C} / \mathrm{N})_{\text {requierd }}$ diklasifikasikan berdasarkan teknik modulasi digitalnya.

Tabel 13. Margin lintasan QPSK frekuensi C-band 


\begin{tabular}{|c|l|c|c|c|c|c|c|}
\hline \multicolumn{2}{|c|}{ Jalur Komunikasi } & \multicolumn{5}{|c|}{$\begin{array}{c}\text { Margin modulasi QPSK } \\
\text { pada Frekuensi C-Band (dB) }\end{array}$} \\
\hline Asal & Tujuan & $\mathbf{9 9 . 9 9 \%}$ & $\mathbf{9 9 . 5 \%}$ & $\mathbf{9 9 . 4 \%}$ & $\mathbf{9 9 . 3 \%}$ & $\mathbf{9 9 . 2 \%}$ & $\mathbf{9 9 . 1 \%}$ \\
\hline \multirow{3}{*}{ Jakarta } & Surabaya & 26,933 & 27,198 & 27,205 & 27,211 & 27,215 & 27,219 \\
\cline { 2 - 8 } & Medan & 26,897 & 27,187 & 27,195 & 27,201 & 27,206 & 27,210 \\
\cline { 2 - 8 } & Makassar & 26,903 & 27,173 & 27,180 & 27,186 & 27,190 & 27,194 \\
\hline \multirow{3}{*}{ Surabaya } & Jakarta & 30,941 & 31,154 & 31,158 & 31,162 & 31,165 & 31,167 \\
\cline { 2 - 8 } & Medan & 26,849 & 27,147 & 27,155 & 27,161 & 27,166 & 27,171 \\
\cline { 2 - 8 } & Makassar & 26,855 & 27,133 & 27,140 & 27,146 & 27,151 & 27,155 \\
\hline \multirow{3}{*}{ Makassary } & Jakarta & 30,935 & 31,153 & 31,158 & 31,161 & 31,164 & 31,167 \\
\cline { 2 - 8 } & Surabaya & 26,883 & 27,158 & 27,165 & 27,171 & 27,175 & 27,180 \\
\cline { 2 - 8 } & Makassar & 26,853 & 27,132 & 27,140 & 27,146 & 27,151 & 27,155 \\
\cline { 2 - 8 } & Jakarta & 30,939 & 31,153 & 31,158 & 31,161 & 31,164 & 31,167 \\
\cline { 2 - 8 } & Medan & 26,884 & 27,158 & 27,165 & 27,171 & 27,175 & 27,179 \\
\cline { 2 - 8 } & 27,849 & 27,147 & 27,155 & 27,161 & 27,166 & 27,170 \\
\hline
\end{tabular}

Lintasan margin untuk sistem komunikasi satelit yang bekerja pada frekuensi C-band dengan mengimplementasikan QPSK, 8PSK, dan 16QAM dapat diterapkan pada keenam availability $99,1 \%$, $99,2 \%, 99,3 \%, 99,4 \%, 99,5 \%$, dan 99,99\%. Terlihat bahwa semua kemungkinan komunikasi menggunakan frekuensi ini memberikan margin yang sangat baik di atas $26 \mathrm{~dB}$.

Sementara itu, komunikasi satelit menggunakan pita frekuensi Ka tidak semua jalur komunikasinya memiliki margin. Margin untuk lintasan yang aman berkomunikasi pada sistem komunikasi ini adalah informasi yang melalui stasiun Hub Jakarta. Margin tersebut berada di atas $16 \mathrm{~dB}$ untuk pengamatan selain dari $0,01 \%$.

Tabel 14. Margin lintasan QPSK frekuensi Ka-band

\begin{tabular}{|c|l|r|r|r|r|r|r|}
\hline \multicolumn{2}{|c|}{ Jalur Komunikasi } & \multicolumn{5}{|c|}{$\begin{array}{c}\text { Margin modulasi QPSK } \\
\text { pada Frekuensi Ka-Band (dB) }\end{array}$} \\
\hline Asal & Tujuan & $\mathbf{9 9 . 9 9 \%}$ & $\mathbf{9 9 . 5 \%}$ & $\mathbf{9 9 . 4 \%}$ & $\mathbf{9 9 . 3 \%}$ & $\mathbf{9 9 . 2 \%}$ & $\mathbf{9 9 . 1 \%}$ \\
\hline \multirow{3}{*}{ Jakarta } & Surabaya & 1,089 & 16,416 & 16,886 & 17,260 & 17,565 & 17,819 \\
\cline { 2 - 8 } & Medan & 0,521 & 16,094 & 16,613 & 17,028 & 17,369 & 17,652 \\
\cline { 2 - 8 } & Makassar & 1,036 & 16,348 & 16,827 & 17,209 & 17,520 & 17,779 \\
\hline \multirow{3}{*}{ Surabaya } & Jakarta & $-21,026$ & 0,490 & 1,267 & 1,895 & 2,413 & 2,848 \\
\cline { 2 - 8 } & Medan & $-21,036$ & 0,411 & 1,183 & 1,805 & 2,318 & 2,749 \\
\cline { 2 - 8 } & Makassar & $-21,033$ & 0,418 & 1,189 & 1,810 & 2,323 & 2,753 \\
\hline \multirow{3}{*}{ Medan } & Jakarta & $-24,770$ & $-0,589$ & 0,367 & 1,140 & 1,779 & 2,315 \\
\cline { 2 - 8 } & Surabaya & $-24,773$ & $-0,644$ & 0,304 & 1,070 & 1,703 & 2,232 \\
\cline { 2 - 8 } & Makassar & $-24,773$ & $-0,645$ & 0,303 & 1,069 & 1,701 & 2,231 \\
\hline & Jakarta & $-21,493$ & 0,269 & 1,084 & 1,742 & 2,285 & 2,741 \\
\cline { 2 - 8 } & Surabaya & $-21,499$ & 0,202 & 1,010 & 1,661 & 2,199 & 2,649 \\
\cline { 2 - 8 } & Medan & $-21,502$ & 0,194 & 1,002 & 1,655 & 2,193 & 2,644 \\
\hline
\end{tabular}

\section{KESIMPULAN}

Komunikasi satelit C-band untuk ketiga teknik modulasi terbukti handal dalam melayani komunikasi di keempat wilayah Indonesia yaitu Jakarta, Medan, Surabaya dan Makassar untuk semua waktu pengamatan. Sementara itu, komunikasi satelit Ka-band tetap aman diterapkan di wilayah-wiayah tersebut untuk komunikasi yang melalui stasiun Hub Jakarta pada availability 99, $1 \%$ - 99,5\%. Pengembangan penelitian ini dapat dilakukan dengan meninjau penempatan satelit di orbit tertentu dan persen waktu pengamatan yang lainnya serta memperhatikan diversitas stasiun bumi berjarak tertentu pada suatu wilayah untuk mengantisipasi curah hujan tinggi.

\section{DAFTAR PUSTAKA}

[1] A. A. Atayero, "Satellite link design: A tutorial," Int. J. Electr. Comput. Sci. IJECSIJENS, vol. 11, no. 4, 2011.

[2] Z. B. Hasanuddin, "Design of Ka-band Satellite Links in Indonesia," J. Electr. Comput. Energ. Electron. Commun. Eng., vol. 8, no. 8, 2014.

[3] M. M. J. L. van de Kamp, J. K. Tervonen, E. T. Salonen, and J. P. V. P. Baptista, "Improved models for long-term prediction of tropospheric scintillation on slant paths," IEEE Trans. Antennas Propag., vol. 47, no. 2, pp. 249-260, 1999.

[4] R. L. Freeman, Radio system design for telecommunications, vol. 98. John Wiley \& Sons, 2006.

[5] J. S. Ojo, M. O. Ajewole, and S. K. Sarkar, "Rain rate and rain attenuation prediction for satellite communication in $\mathrm{Ku}$ and $\mathrm{Ka}$ bands over Nigeria.," Prog. Electromagn. Res., vol. 5, pp. 207-223, 2008.

[6] J. Christensen, "Itu regulations for ka-band satellite networks," in 30th AIAA International Communications Satellite System Conference (ICSSC), 2012, p. 15179.

[7] A. K. Kundu, M. T. H. Khan, W. Sharmin, M. O. Goni, and K. A. Barket, "Designing a mobile satellite communication Antenna and Link Budget Optimization," in 2013 International Conference on Electrical Information and Communication Technology (EICT), 2014, pp. $1-6$.

[8] Y. Tepetam, “Analysis of Turkish communications sector and determination of critical success factors," NAVAL POSTGRADUATE SCHOOL MONTEREY CA, 2014.

[9] P. Series, "Propagation data and prediction methods required for the design of Earth-space telecommunication systems," Recomm. ITU-R, pp. 612-618, 2015. 